\section{Anti-coagulation in Atrial Fibrillation: Warfarin Vs NOACs}

I read with interest the editorial: "Paradigm Shift in AntiCoagulating Patients with Non-Valvular Atrial Fibrillation" by Prof. Bushra Moiz in your prestigious journal. ${ }^{1}$ Scientific literature about anti-coagulation in atrial fibrillation also resonates with the facts stated in the editorial. I wish to add to this topic by sharing some important points. Firstly, it is recommended to commence warfarin initially (whether for atrial fibrillation or venous thromboembolism) with unfractionated heparin or low molecular weight heparin (LMWH) until international normalized ratio (INR) becomes therapeutic, ${ }^{2}$ which is also a reason some patients prefer novel oral anti-coagulents (NOACs) over warfarin. Secondly, if anti-coagulation in atrial fibrillation is contraindicated, then it is important to offer a combination of aspirin and clopidogrel. ${ }^{3}$ Thirdly, there is limited data regarding the comparison between warfarin and NOACs, looking at effectiveness and safety, in Asians, ${ }^{4}$ more so amongst the population of Indian subcontinent. So, it is imperative that a multicentre national research effort is undertaken to bring out the facts regarding our population cohort.

\section{CONFLICT OF INTEREST:}

Author declared no conflict of interest.

AUTHOR'S CONTRIBUTION:

BHM: Conceived, written and submitted the manuscript.

\section{REFERENCES}

1. Moiz B. Paradigm shift in anti-coagulating patients with nonvalvular atrial fibrillation. J Coll Physicians Surg Pak 2019; 29:2-3.

2. du Breuil AL, Umland EM. Outpatient management of anticoagulation therapy. Am Fam Physician 2007; 75:1031-42.

3. NICE Guidelines, CKS, Atrial fibrillation, Scenario: First or new presentation of AF. Revised Feb 2018.

4. Cha MJ, Choi EK, Han KD, Lee SR, Lim WH, Oh S, et al. Effectiveness and safety of non-vitamin $\mathrm{K}$ antagonist oral anticoagulants in Asian patients with atrial fibrillation. Stroke 2017; 48:3040-8

Bilal Haider Malik

Higher Specialist Trainee in Geriatric Medicine, UK

Correspondence to: Dr. Bilal Haider Malik, 7 Eden Drive, Colchester, CO4 6AY, UK

E-mail: cardbilal88@gmail.com

Received: January 24, 2019; Revised: February 27, 2019;

Accepted: February 27, 2019

\section{Author's Reply:}

I thank the reader for taking interest in the editorial "Paradigm shift in anti-coagulating patients with nonvalvular atrial fibrillation" published in JCPSP, January
2019 issue. The reader has raised several important issues regarding novel oral anticoagulants (NOACs) for which my response is as follows:

1. Vitamin K-antagonists (VKAs) take 48 to 72 hours for their onset of action and, therefore, require bridging with heparin for anticoagulating patients. Unlike VKAs, anticoagulation effect of NOACs is observed within 3 hours of their administration; hence, they are given directly without prior heparinization. ${ }^{1}$

2. We should be mindful of the fact that dual antiplatelet therapy (DAPT) and oral anticoagulation bear a comparable bleeding risk. Therefore, a patient who is not a candidate for oral anticoagulation because of bleeding risk cannot be a candidate for DAPT. DAPT may be a reasonable alternative to therapy with aspirin alone in the occasional high-risk patient with atrial fibrillation who cannot be treated with anti-coagulation because of patient or physician preferences. ${ }^{2}$ With the availability of the NOAC agents, this condition should be extremely exceptional.

3. The three clinical trials for evaluating safety and efficacy of NOACs randomised a total of 44,563 subjects. The studies were global and multi-centric; for example, in dabigatran trial, patients were recruited from 951 clinical centres residing in 44 countries including India. ${ }^{3}$ Similarly, 14,264 patients were enrolled in the doubleblind multi-national study on rivaroxaban and included patients from Asian countries such as China, India, Turkey, Taiwan, Hong Kong, Thailand and so on. ${ }^{4}$ These studies did not show differences in their endpoints for ethnicity. In light of these evidences and in my personal experience, NOACs are effective in our population.

\section{REFERENCES}

1. Heidbuchel $H$, Verhamme $P$, Alings $M$, Antz M, Hacke W, Oldgren $\mathrm{J}$, et al. European heart rhythm association practical guide on the use of new oral anticoagulants in patients with non-valvular atrial fibrillation. Europace 2013; 15:625-51.

2. Anderson JL, Halperin JL, Albert NM, Bozkurt B, Brindis RG, Curtis $\mathrm{LH}$, et al. Management of patients with atrial fibrillation (compilation of 2006 ACCF/AHA/ESC and 2011 ACCF/AHA/ HRS recommendations): A report of the American College of Cardiology/American Heart Association Task Force on practice guidelines. J Am Coll Cardiol 2013; 61:1935-44.

3. Connolly SJ, Ezekowitz MD, Yusuf S, Eikelboom J, Oldgren J, Parekh A, et al. Dabigatran versus warfarin in patients with atrial fibrillation. N Engl J Med 2009; 361:1139-51.

4. Patel MR, Mahaffey KW, Garg J, Pan G, Singer DE, Hacke W, et al. Rivaroxaban versus warfarin in nonvalvular atrial fibrillation. N Engl J Med 2011; 365:883-91.

Bushra Moiz

Department of Pathology and Laboratory Medicine, The Aga Khan University, Karachi, Pakistan

Correspondence to: Prof. Bushra Moiz, Department of Pathology and Laboratory Medicine, The Aga Khan University, Karachi,

Pakistan

E-mail: bushra.moiz@aku.edu 